\title{
FORMAÇÃO EMPREENDEDORA NA PERSPECTIVA DA APRENDIZAGEM BASEADA EM PROJETOS: RELATO DE EXPERIÊNCIA EM UMA INSTITUIÇÃO DE ENSINO SUPERIOR NO CEARÁ
}

Antonia Márcia Rodrigues Sousa ${ }^{1}$

Roosiley Santos Souza ${ }^{1}$

Fabiana Pinto De Almeida Bizarria ${ }^{2}$

Alexandre Oliveira Lima ${ }^{2}$

\footnotetext{
${ }^{1}$ Universidade Federal de Mato Grosso do Sul

${ }^{2}$ Universidade da Integração Internacional da Lusofonia Afro-Brasileira
} 


\section{FORMAÇÃO EMPREENDEDORA NA PERSPECTIVA DA APRENDIZAGEM BASEADA EM PROJETOS: RELATO DE EXPERIÊNCIA EM UMA INSTITUIÇÃO DE ENSINO SUPERIOR NO CEARÁ}

\section{RESUMO}

O estimulo a tomada decisões, liberdade para resolução de problemas, autonomia e o incentivo a vivência de experiências reais e simuladas, são aspectos comportamentais inerentes a formação empreendedora que vem sendo trabalhada na Aprendizagem Baseada em Projetos visando a formação de profissionais mais autônomos. Nessa ótica, o objetivo deste estudo é descrever a experiência de um projeto de incentivo a formação empreendedora implantado por meio da Aprendizagem Baseada em Projetos em uma instituição de ensino superior no Ceará. Metodologicamente é uma pesquisa-ação, realizada anual em um projeto denominado EXPOVENDAS, com a participação de alunos e professores. Para a coleta de dados, utilizou-se o método de triangulação. Os resultados apontam que o uso dessa metodologia ativa tornou-se para os alunos uma janela de oportunidades ao desenvolver a capacidade crítica e autonomia para expressar suas habilidades e competências enquanto agente construtor da sua própria aprendizagem otimizando a sua capacidade para empreender.

Palavras-chave: Formação empreendedora. Aprendizagem Baseada em Projetos. Metodologia ativa.

\section{INTRODUÇÃO}

O empreendedorismo vem sendo fomentado sobre distintas formas em espaços de aprendizagem formal e informal como mecanismo de estimulo entre os indivíduos com fins a ampliar o desenvolvimento de ações e a geração de oportunidade capaz de contribuir para a formação empreendedora levando ou não à criação de novos negócios.

Nessa ótica, as Instituições de Ensino Superior (IES) funcionam como órgãos mediadores da relação entre o processo de ensino e aprendizagem responsáveis por integralizar a teoria à prática por meio do desenvolvimento de políticas e programas educacionais orientados para o empreendedorismo, com o objetivo de estimular valores empreendedores e disseminar a cultura empreendedora como fator de desenvolvimento econômico (BARON; SHANE, 2007).

De acordo com a Organização das Nações Unidas - ONU (2013), o objetivo de políticas de formação de empreendedores não está ligado apenas a fomentar a capacidade e o desejo de criar uma empresa, mas de formar uma cultura empreendedora no seio social. Nesse sentido, é imprescindível a criação de atividades extracurriculares interdisciplinares que conduzam o aluno a uma formação de "educar para empreender" e não "ensinar para empreender".

Para isso, é necessário que os professores adotem práticas e metodologias que envolva o aluno a atuar encorajado e inspirado para desenvolver atividades que exija sagacidade e tomada de decisão. O método de Aprendizagem Baseada em Projetos (ABP) como uma das metodologias ativas que integra o aluno ao seu processo de aprendizagem ao instigar o
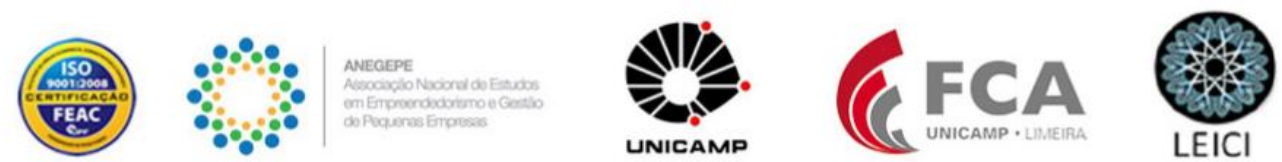
envolvimento em atividades que exige competências e habilidades para protagonizar ações reais que não são permitidas nas aulas tradicionais, torna-se um disseminador de comportamentos para formação empreendedora do aluno. Essa metodologia de aprendizagem coloca o aluno em um ambiente desafiador com tarefas emancipatórias que variam de criação de um projeto, produto, ou situação de simulação real.

Assim, argumenta-se que um ambiente propício a formação empreendedora no âmbito do ensino superior é o que coloca o aluno como parte integrante da sua aprendizagem, em que o professor passa a ser um mediador desse processo. Tal referência tem livre associação com conceito de aprendizagem defendido por Kolb $(1984$, p.123) de que "a aprendizagem é o processo por onde ocorre o desenvolvimento", ou seja, o percurso do aprender resulta da ação humana sobre o ambiente. Em virtude disso, a problemática trabalhada ao longo dos anos é: Como fomentar a formação empreendedora num ambiente permeado por valores culturais do emprego tradicional? Nessa perspectiva, o objetivo deste estudo é descrever a experiência de um projeto de incentivo a formação empreendedora implantado por meio da $\mathrm{ABP}$.

A implantação dessa metodologia teve como justificativa contribuir para uma efetiva prática de formação empreendedora de alunos de curso de graduação em Administração em uma Instituição de Ensino Superior privada, situada no semiárido do Nordeste Brasileiro, na cidade de Sobral, Estado do Ceará, distante $280 \mathrm{~km}$ da Capital Fortaleza.

O projeto denominado de EXPOVENDAS está implantado desde 2009, a idealização e implantação surgiu da inquietação da instituição e dos professores em relação a uma formação efetiva que possibilitasse a identificação de oportunidades dentro dos mais distintos potenciais de mercado da região.

O potencial de oportunidades voltadas a criação de novos negócios oriundo das suas particularidades como maior cidade polo da região noroeste do Ceará com mais 200 mil habitantes, estando entre as 30 cidades com melhores condições para se morar, trabalhar e estudar (IBGE, 2010). Em 2011 ficou no ranking da REVISTA BRITÂNICA FDI Magazine Times entre as seis cidades com as melhores perspectivas para investimento estrangeiro, desenvolvimento econômico e expansão de negócios. Em 2017 ficou entre as dez cidades com os melhores Índices de Oportunidades da Educação Brasileira (Ioebs), segundo o - Centro de Liderança Pública (CLP).

Ainda de acordo com um estudo da "American Cities of The Futres 2017/2018" a cidade ocupa a segunda posição entre as pequenas cidades das Américas com melhor relação custo-eficácia, ficando apenas atrás da pequena cidade de Potosí, na Bolívia. Importante ressaltar que os indicadores de avaliação para o ranking, são os salários, preços de aluguel comercial, custo de eletricidade, custos de construção, taxas, impostos, dentre outros.

Tomando como base essa representatividade, em 2009, definiu-se com os gestores, professores e alunos da IES, que seria implantado um projeto anualmente no curso de Administração, com o propósito de desenvolver e orientar o comportamento empreendedor dos alunos por meio de discussões teóricas e exposição prática e de formação nos mais distintos aspectos do empreendedorismo.

O presente artigo está estruturado da seguinte forma: a primeira sessão apresenta as considerações introdutórias e o propósito do estudo, na sessão seguinte, os construtos teóricos sobre empreendedorismo alinhado a formação empreendedora e o método de Aprendizagem Baseado em Problemas, Aprendizagem Baseada em Projetos e a Prática de Formação

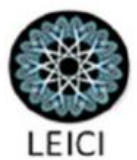


Empreendedora. Em seguida o delineamento metodológico, a aplicação e as principais considerações. Na última sessão tece as reflexões sobre os resultados, as limitações do estudo e proposições para estudos futuros.

\section{FUNDAMENTAÇÃO TEÓRICA 2.1 EMPREENDEDORISMO E FORMAÇÃO EMPREENDEDORA}

No campo teórico, as definições de empreendedorismo e educação empreendedora vêm apresentando uma evolução cronológica com diferentes concepções e contextos distintos, porém associados às correntes dos economistas e comportamentalistas.

Com uma argumentação conjunta, o comportamento do empreendedor é definido como alguém que identifica uma oportunidade, gera uma ideia inovadora, integrando uma combinação de recursos com a geração de lucros, sob condições de riscos financeiros e incertezas psicológicas e sociais (DORNELAS, 2001; DEGEN, 1989; HIRISCH; PETER, 2009).

Para Schumpeter (1982), a essência do empreendedorismo está na percepção e no aprimoramento das novas oportunidades no âmbito dos negócios, considerando a criação de uma nova forma de uso dos recursos, em que eles sejam deslocados da forma do emprego tradicional e sujeitos a novas combinações.

A dinâmica social e econômica contemporânea direciona o indivíduo a identificar em suas características pessoais uma intenção à ação empreendedora, seja por influência do círculo de relações, por necessidades de mudanças, pela falta de postos de trabalho ou pelo instinto nato de desenvolver o espírito empreendedor (DOLABELA, 1999).

Gibb (1995) caracteriza o empreendedor como um indivíduo que tem uma visão e um senso de identificação de oportunidades, compromete-se com ela e a conduz, pelo caminho solitário, até que consiga implementá-la de forma criativa e inovadora, conduzindo ao sucesso.

O empreendedorismo tem distintas possibilidades de estudo, entretanto Shane e Venkataraman (2000) definem com a busca pela oportunidade na intenção de criar algo novo a partir das inquietações do indivíduo que de forma criativa e inovadora aproveita as potencialidades locais para atingir seu propósito.

Deste modo, os empreendedores se destacam não apenas como um indivíduo apto a visualizar oportunidades de negócios que impulsionam a economia, mas como modelos de profissionais criativos e inovadores que por meio das suas descobertas que agregam valor ao país por meio das forças direcionadoras do desenvolvimento econômico e social.

O empreendedorismo alavanca a economia global, promove o desenvolvimento econômico e social do país (GEM, 2015; Vanevenhoven, 2013) ao criar algo inovador capaz de gerar mudanças no ambiente por meio da organização e reorganização do uso de recursos locais.

Nessa ótica, formar empreendedores com consciência econômica e social de aproveitar as potencialidades da sua região, implica repensar os métodos de aprendizagem que vem sendo aplicados por instituições de ensino que disseminam a relevância do empreender como um propulsor do desenvolvimento econômico de muitas regiões que tem como meio de sobrevivência os recursos financeiros advindos do setor público.
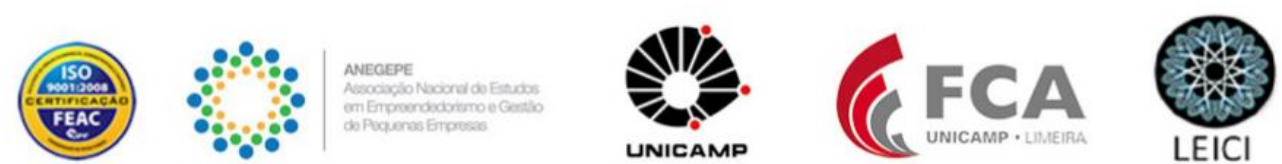
Para isso Dolabela; Filion, (2013); Lima et. al. (2015), advogam a necessidade de uma reestruturação metodológica do ensino tradicional para um ensino centrado na participação ativa do indivíduo. Entretanto, para que essas mudanças ocorram de forma satisfatória, são necessárias mudanças de práticas pedagógicas, grade curricular e especificamente a cultura e a mentalidade dos professores que foram formados e continuamente retroalimentam sua identidade profissional com capacitações que exigem da sua prática uma reprodução teórica descontextualizada para um mercado que busca profissionais que atuem de forma ativa e colaborativa.

O uso das metodologias ativas vem sendo utilizada como uma das ferramentas de mudanças e adaptações nos objetivos educacionais e de estruturas curriculares de algumas instituições de ensino com a concepção de que a formação baseada nesse estimulo participativo e integrador agregará um valor diferenciado, propiciando o aluno a desenvolver seu senso crítico e participar ativamente da sua aprendizagem.

$\mathrm{Na}$ visão de Borhan (2014), o uso das metodologias ativas, seja por meio do método abordado na Aprendizagem Baseada em Problemas - (PBL), Aprendizagem Baseada em Projetos - $(\mathrm{ABP})$ ou na Aprendizagem Baseada em Equipes- (ABE), é interessante por estimular o aluno a desenvolver o pensamento crítico, a capacidade de resolutividade, as mutabilidades e adaptabilidades do mercado, em conformidades com a propensão a trabalhar em equipe de forma criativa e inovadora, vertentes essenciais para empreender.

Em relação aos processos que envolvem a capacidade de aprender, (Freire, 2003, p.69), afirma que essa ação "não consiste apenas a um processo adaptativo, mas, sobretudo para transformar a realidade, para nela intervir.

Ao trazer essa vertente para a seara empreendedora, cabe associar as recomendações da UNESCO para a educação do século XXI: aprender a conhecer, aprender a fazer, aprender a conviver e aprender a ser, tendo em vista que se esses processos ocorrem de forma em que os professores priorizam distintas abordagens vivenciais e dinâmicas (Hashimoto, 2013), permitindo o aluno a explorar experiências, interagindo diretamente com as potencialidades e fragilidades da sua aprendizagem.

Além disso, o aluno se torna o agente idealizador e construtor da sua própria aprendizagem, possibilitando desenvolver competências e habilidades que atendam aos requisitos de um profissional autônomo (Berbel, 2011) sustentado por características e comportamentos de um indivíduo inovador, que retém conhecimento, idealiza e desenvolve projetos e reage a qualquer a mudança (LOPES; TEIXEIRA, 2010).

A equalização dessas características, consolida uma independência dos métodos tradicionais de aprendizagem ao permitir o aluno transpor as barreiras encontradas no isolamento da teoria com a vida real. Assim, é possível que "os educandos vão se transformando em reais sujeitos da construção e da reconstrução do saber ensinado, ao lado do educador, igualmente sujeito do processo" (FREIRE, 2003, p.26).

Porém, para que isso ocorra é fundamental a existência de professores com perfis visionários e realizadores que Lima et. al. (2014) advogam ser os geradores de impacto na educação empreendedora ao apresentarem convergências entre a teoria e a prática por meio da amplitude dos projetos que empreendem.

No âmbito dessa discussão acerca do professor como um agente condutor de práticas que orientam a formação para o empreendedorismo, Tschá; Cruz Neto (2014), evidenciam

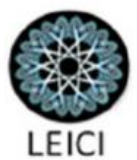


que os professores passam a ser vistos sob a ótica de um líder, mentor e conselheiro que atuam de forma colaborativa ao estimular, inspirar, criar ou orientar ideias ou outras atividades práticas que levam os alunos a vivenciarem sua própria aprendizagem.

\subsection{APRENDIZAGEM BASEADA EM PROJETOS - ABP}

As metodologias ativas de aprendizagem têm como estratégia o envolvimento do aluno na concepção de uma atividade que deve alinhar teoria à prática, identificando mecanismos centrais de como executar por meio do uso da aprendizagem preconcebida (GRAFF; KOLMOS, 2007; BOTHA, 2010).

Essa interpretação, foca nas dificuldades de aprendizagem encontradas pela geração $Y$ e $\mathrm{Z}$ de manter-se concentradas em sala de aula durante a exposição dos métodos tradicionais de ensino, onde o principal objetivo é a transmissão de informações (Cardoso; Lima, 2012) excluindo, a utilização e a integração à prática cotidiana desses jovens que buscam na educação uma alternativa para inserção no mercado de trabalho.

Nessa concepção de ensinar, se apropriando do comportamento crítico, das habilidades e do estímulo do aluno, a buscar seus próprios conhecimentos, algumas metodologias ativas vem sendo utilizadas como mecanismos de reter a atenção do aluno. Dentre tais as mais identificadas na literatura está a Aprendizagem Baseada em Problemas - (PBL), Aprendizagem Baseada em Projetos - (ABP) ou na Aprendizagem Baseada em Equipes(ABE).

O crescente uso das metodologias ativas indica uma reconstrução ou adaptação de um formato de ensino tradicional para uma proposta pedagógica que coloca o aluno como um agente ativamente envolvido nas ações implementadas em sala de aula. Possibilitando maior envolvimento no processo de aprendizagem por meio dos distintos significados práticos dados aos conteúdos como estratégia de liberdade de aprender por meio da construção do fazer, pautado numa práxis educativa de discussão, análise e diferentes soluções para distintos problemas.

Para esse estudo, a abordagem é na Aprendizagem Baseada em Projetos -(ABP) que tem suas origens a partir das ideias de John Dewey (1916) e defende que o aluno para aprender necessita de um ambiente que remonta a uma situação ativa na vida real e que provoque um sentido e um propósito para esse aprendizado.

A aplicação dessa metodologia envolve o aluno como agente co-participante da sua aprendizagem, promovendo o preenchimento de uma lacuna existente nas salas de aula, onde o aluno expressa veementemente resistência aos modelos tradicionais de ensino. É uma forma de romper com as aulas tradicionais ainda muito recorrente no seio das instituições de ensino, em prol de aderir as exigências do mercado, que requer profissionais proativos, com capacidade para tomar decisão, alta resolutividade, espirito de equipe, aprendizagem autônoma capacidade de se adequar as constantes mutações do mercado (CASALE, 2013).

Para Libâneo (2011) é urgente a necessidade das instituições de ensino em oferecer um ambiente que promova a inserção de aulas que estimule os aspectos cognitivos dos alunos, oportunizando o desenvolvimento de competências e habilidades que sustentarão sua prática profissional.
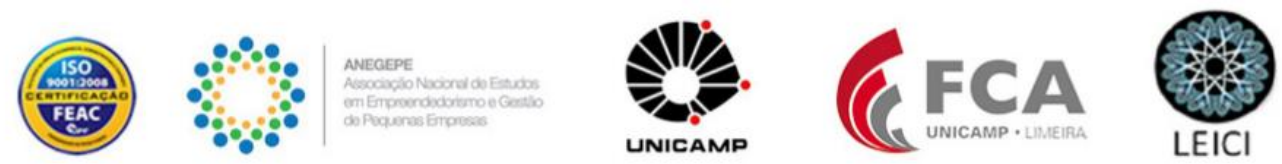
Essa adequação metodológica das instituições de ensino as demandas do mercado, possibilita ao aluno vivenciar experiências reais ou simuladas que servirão de base para uma formação profissional sólida e coerente com os desafios postos pela realidade.

Essa interseção dos métodos tradicionais e ativos atua como uma estratégia motivadora para os alunos, permitindo uma experimentação de aprender fazendo, estilo de aprendizagem defendido por Kolb (1994) ao afirmar que "O processo de aprendizagem advindo da experiência determina e atualiza o desenvolvimento potencial" (Kolb, 1984, p. 133). Para o autor, o indivíduo tem propensão a aprender, a conhecer e desenvolver a partir de diversos estilos. E apresenta o ciclo de aprendizagem que integra quatro modelos adaptativos de aprendizagem, a experiência concreta(EC), Observação reflexiva (OR), Conceituação abstrata (AC) e Experiência ativa (EA). As proposições de Kolb (1984) propõe distintas formas de pensar a aprendizagem, mostrando a necessidade de considerar nesse processo, as competências cognitivas, pessoais e sociais (Perrenoud, 2002) que nem sempre são demonstradas por meio do método tradicional.

Demo (2010) defende que aprender a aprender é uma competência que está relacionada com a aprendizagem e ocorre por meio de uma série de fatores que são estimulados ao longo da vida e que não se aprende por meio convencional, é necessário uma interação com o ambiente como forma de desenvolver características que estejam associadas a proatividade, inovação, liderança, visão empreendedora, trabalho em equipe, dentre outras.

Nessa ótica, a aprendizagem baseada em projetos por se apropriar de metodologias construtivistas e alinhar a competência, instiga o aluno a desenvolver tarefas com alto grau de complexidade, propondo questões desafiadoras com as quais criam produtos, processos ou sistemas, analisam e aplicam teorias no seu desenvolvimento com associações relacionadas ao seu cotidiano (WEENK ; VAN DER BLIJ, 2011).

O ensino por projetos garante a aprendizagem pela aproximação da teoria com a prática, permitindo uma abordagem emancipatória, que conduz o aluno a contextualizar a teoria com o seu cotidiano e construir estratégias de ação que estimulam na adoção de tomada de decisão, flexibilização ao riscos e incertezas, autonomia, autoconfiança, visão sistêmica e formação empreendedora (HERNANDEZ; VENTURA 1998; ARAÚJO, 2008).

A aprendizagem baseada em Projetos ao envolver o aluno no seu processo de aprendizagem está contribuindo para formar um indivíduo empreendedor, que na visão de Filion (1999) é a pessoa que imagina, desenvolve e realiza visões com alto grau de capacidade criativa e de estabelecimentos de metas calcadas na perspectiva de detectar oportunidades para criação de novos negócios.

Nessa ótica, o uso das metodologias ativas como um processo interativo que se utiliza de experiências reais e simuladas com a finalidade de extrair do aluno características de adaptabilidade, iniciativa, segurança e tomada de decisões na solução de problemas oriundo de atividades inerentes a sua formação profissional nos distintos contextos que surgirem ao longo da sua vida profissional, ao ser trabalhada por meio de uma ou mais disciplinas, contribuem para a formação empreendedora do aluno ao estimular esse aprendizado participativo.

Para Dolabela e Filion (2013) os empreendedores são orientados para ação, ou seja, as "experiências individuais, coletivas de imitação e de comunicação com outras pessoas e de interação com o ambiente físico" defendidas por (Kolb, 1984, p. 133) em congruência com a

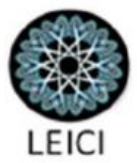


abordagem comportamental do aprender fazendo no modelo de Aprendizagem Baseada em Problemas, apresentam implícitos elementos que contribuem no estimulo a comportamentos, características, competência e educação para o empreendedorismo.

\section{PRÁTICA DE FORMAÇÃO EMPREENDEDORA}

O projeto EXPOVENDAS foi criado em 2009, inicialmente por um grupo de cinco professores sob a orientação da coordenação do curso e a anuência dos gestores da IES, a partir da identificação da necessidade de orientar os alunos numa perspectiva de integrar as teorias abordadas nas disciplinas a uma prática autônoma.

Assim, para que esse processo ocorresse de forma satisfatória para a IES e para os alunos, os professores optaram por trabalhar de forma interdisciplinar colocando o aluno como agente propulsor da sua aprendizagem a partir dos conhecimentos e das competências técnicas adquiridas nas demais disciplinas envolvidas no processo de formação empreendedora.

Inicialmente o aluno tinha a compreensão que estava aprendendo prática de empreendedorismo pela conotação de que o projeto seminalmente estava associado a um planejamento instrucional da disciplina de gestão empreendedora e desenvolvimento local composto na grade curricular do curso como vertente fomentadora para o ensino de empreendedorismo.

Ao longo dos anos, o projeto tornou-se parte estratégica do curso, figurando entre os eventos de natureza institucional inserido no calendário acadêmico, passando a ser uma atividade obrigatória extracurricular do Curso de Administração.

A partir da sua criação em 2009, como atividade prática das disciplinas de "Empreendedorismo e Desenvolvimento Local" e "Gestão das Organizações", outras disciplinas foram integradas, incluindo um processo sistemático de avaliação.

Em 2009 quando implantada teve sua realização no pátio da instituição, denominada de "Feira Empreendedora" com a apresentação e venda de vários produtos em seis stands, organizado em seis grupos formados por seis alunos, sob a orientação da professora que ministrava as primeiras disciplinas envolvidas no projeto.

Em 2010, foram inseridas mais três disciplinas, e passou a ser denominada de "Espaço do Empreendedor", com vendas e exposição de produtos em dez stands, formado por 10 grupos compostos cada um por oito alunos sob a orientação de três professores

Em 2011, com um novo formato, a feira trouxe a temática " Sustentabilidade: Um compromisso coletivo e individual, passando a ser realizada na Boulevard do Arco, um dos pontos turísticos da cidade de Sobral. Com o envolvimento de seis disciplinas formando 10 stands e a participação de 10 alunos em cada, com a orientação de cinco de professores.

Em 2012, com o tema "Empreendedorismo social: transformando sonhos em realidade sustentável" teve a participação de oito disciplinas sob a orientação de oito professores e a formação de 12 grupos, cada um composto por 10 alunos.

Em 2013, com o tema "O empreendedorismo na perspectiva multicultural Brasileira", contou com a participação de 14 grupos, cada um composto por 10 alunos, com a orientação dos professores de 10 distintas disciplinas.
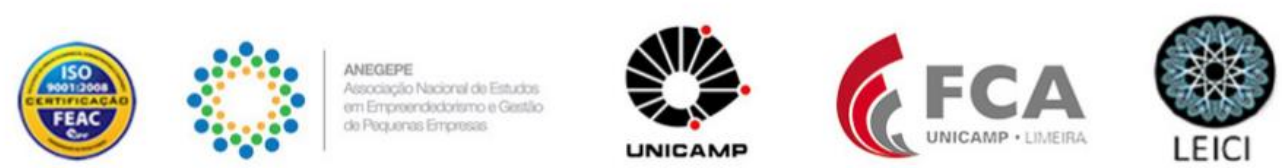
Em 2014, apresentou-se a temática: "Inclusão social na ótica do Empreendedorismo" com a participação de 12 disciplinas e a formação de 18 grupos, composto cada um por 10 alunos. A partir de então, com a implantação de outro projeto, ficou definido que as disciplinas envolvidas para os anos vindouros a metodologia de formação de grupos e orientação dos professores seriam a mesma.

Assim em 2015 sob a orientação dos professores abordou-se o tema: Franquias: Uma alternativa empreendedora consolidada, consorciadas com uma palestra sobre o tema.

Em 2016, com uma visão bem contemporânea o tema foi sobre Economia solidária: Uma alternativa na geração de trabalho e inclusão social. Antes da exposição dos produtos, teve uma mesa redonda onde foi apresentado alguns números da economia solidária na perspectiva local e global.

Em 2017 o tema foi o Empreendedorismo digital: simplificando o mundo digital para que você possa fazer o que ama, quando e onde quiser, seguindo os mesmos critérios de organização dos eventos anteriores. No dia anterior a exposição dos stands, os alunos fizeram uma apresentação teatral abordando a temática em estudo.

A consolidação das atividades ocorreu ao longo dos anos por meio das abordagens descritas na figura 1 - percurso do projeto Expovendas.

Figura 1 - O percurso da Expovendas

\begin{tabular}{|c|c|c|c|}
\hline Ano & Slogan & Disciplinas & Organização \\
\hline 2009 & Feira do Empreendedor & $\begin{array}{l}02 \text { disciplinas de Empreendedorismo e Desenvolvimento } \\
\text { Local" e "Gestão das Organizações" }\end{array}$ & $\begin{array}{l}\text { Seis stands, organizado em seis grupos formados por seis alunos, } \\
\text { sob a orientação de uma professora }\end{array}$ \\
\hline 2010 & Espaço do empreendedor & 05 disciplinas & $\begin{array}{l}\text { Dez stands, dez grupos compostos cada um por oito ahunos e a } \\
\text { orientação de três professores }\end{array}$ \\
\hline 2011 & $\begin{array}{l}\text { Sustentabilidade: Um compromisso coletivo e } \\
\text { individual }\end{array}$ & $\begin{array}{c}06 \text { disciplinas } \\
\text { realizada na Boulevard do Arco, um dos pontos } \\
\text { turisticos da cidade de Sobral }\end{array}$ & $\begin{array}{l}\text { Dez stands e a participação de } 10 \text { ahunos em cada, com a } \\
\text { orientação de cinco de professores }\end{array}$ \\
\hline 2012 & $\begin{array}{l}\text { Empreendedorismo social transformando sonhos em } \\
\text { realidade sustentável }\end{array}$ & 08 disciplinas & $\begin{array}{l}\text { Oito professores e a formação de } 12 \text { grupos, cada um composto } \\
\text { por } 10 \text { ahnos }\end{array}$ \\
\hline 2013 & $\begin{array}{l}\text { O empreendedorismo na perspectiva multicultural } \\
\text { Brasileira }\end{array}$ & 10 disciplinas & $\begin{array}{l}14 \text { grupos, cada um composto por } 10 \text { ahunos, com a orientação } \\
\text { dos professores de } 10 \text { distintas disciplinas }\end{array}$ \\
\hline 2014 & Inchusão social na ótica do Empreendedorismo & 12 disciplinas & 18 grupos, composto cada um por 10 ahunos \\
\hline 2015 & $\begin{array}{l}\text { Franquias: Uma alternativa empreendedora } \\
\text { consolidada }\end{array}$ & 12 disciplinas & 18 grupos, composto cada um por 10 alunos \\
\hline 2016 & $\begin{array}{l}\text { Economia solidária: Uma alternativa na geração de } \\
\text { trabalho e inchusão social }\end{array}$ & 12 disciplinas & 18 grupos, composto cada um por 10 ahnos \\
\hline 2017 & $\begin{array}{l}\text { Empreendedorismo digital: simplificando o mundo } \\
\text { digital para que você possa fazer o que ama, quando } \\
\text { e onde quiser. }\end{array}$ & 12 disciplinas & 18 grupos, composto cada um por 10 ahnos \\
\hline
\end{tabular}

Fonte: Elaborado pelos autores (2018)

Nessa ótica, a Expovendas tornou-se uma atividade prática anual obrigatória para os estudantes. Portanto, a formação empreendedora do aluno ocorre a partir do ingresso no curso com uma fase de preparação e observação das atividades desenvolvidas de cunho preparatório para a implementação do projeto que acontece anualmente durante dois dias na segunda 
quinzena de maio. O dia que antecede a exposição e vendas dos produtos é destinado para que os alunos apresentem a temática do projeto, seja por meio de palestras, mesa redonda ou apresentação lúdica, essa definição faz parte da tomada de decisão coletiva dos alunos.

A operacionalização ocorre a partir das seguintes etapas, conforme figura 2 planejamento e prática empreendedora.

\begin{tabular}{|c|c|c|c|}
\hline $\begin{array}{c}\text { Etapas } \\
\text { de execução }\end{array}$ & Atividade & Instrumentalização & Responsáveis \\
\hline 1 & Definição do tema com base na problemática do projeto & $\begin{array}{l}\text { Apresentação e discussão sobre os temas } \\
\text { emergentes de formação empreendedora }\end{array}$ & Professores tutores $\mathrm{e}$ ahnos \\
\hline 2 & Formação das equipes & $\begin{array}{l}\text { Por livre iniciativa dos ahunos e mediados } \\
\text { por doze professores são formados } 18 \text { grupos, } \\
\text { cada um composto por } 10 \text { alunos integrados } \\
\text { entre semestres que varia do segundo ao oitavo } \\
\text { semestre. }\end{array}$ & Professores tutores e ahnos \\
\hline 3 & Escolha do aluno-tutor & $\begin{array}{l}\text { São escollhidos por critérios das equipes, } \\
18 \text { ahunos-tutores. }\end{array}$ & Alunos \\
\hline 4 & Base teórica & $\begin{array}{l}\text { Os conteúdos são definidos de forma } \\
\text { interdisciplinar com abordagem especifica da } \\
\text { disciplina e da proposta do projeto. }\end{array}$ & Professor-tutor \\
\hline 5 & Workshop para definição das tarefas & $\begin{array}{l}\text { É um processo de delegação de } \\
\text { responsabilidades aos ahunos, onde irão se } \\
\text { envolver na construção da resolução do } \\
\text { problema usando o pensamento critico, } \\
\text { iniciativa, rede de relações, trabalho em equipe. }\end{array}$ & Professor-tutor e aluno-tutor \\
\hline 6 & Controle das tarefas & $\begin{array}{l}\text { Ocorre por meio da apresentação de } \\
\text { métodos, ferramentas gerenciais e habilidades } \\
\text { interpessoais na efetivação da tarefa. }\end{array}$ & Professor-tutor e aluno-tutor \\
\hline 7 & Projeto final & $\begin{array}{l}\text { Apresentação prévia do que será } \\
\text { realizado na finalização do projeto que resulta na } \\
\text { exposição dos produtos }\end{array}$ & Aluno-tutor e os demais ahnos \\
\hline 8 & Apresentação dos produtos & $\begin{array}{l}\text { A finalização do projeto ocorre com a } \\
\text { exposição e vendas de produtos divididos em } 18 \\
\text { stands cada um formado por um grupo de dez } \\
\text { alunos que envolvem duas ou três disciplinas, } \\
\text { sob a orientação de dois ou três professores. }\end{array}$ & $\begin{array}{l}\text { Professor-tutor;Aluno-tutor e os demais } \\
\text { alunos }\end{array}$ \\
\hline 9 & Avaliação & $\begin{array}{c}\text { Ocorre após a finalização do projeto, } \\
\text { onde os ahunos expõem como ocorreu o processo } \\
\text { de ensino-aprendizagem e suas contribuições } \\
\text { para a sua formação como futuros } \\
\text { amnraendernrac }\end{array}$ & Professores tutores $\mathrm{e}$ ahnos \\
\hline
\end{tabular}

Fonte: Autores (2018)

A prática de aprendizagem ativa implantada a partir desse projeto está centrada na ideia de Delors (2006) ao sinalizar em seu estudo que a missão dos educadores no contexto geral é democratizar o conhecimento para reduzir as desigualdades e oportunizar novas práticas de aprender a conhecer, fazer, viver juntos e ser um agente transformador de ideias em oportunidades criativas e inovadoras.

\section{DESCRIÇÃO METODOLÓGICA}

O design metodológico desse relato de experiência foi a pesquisa-ação, que segundo Chizzotti (2006) está representada por seis fases: identificação do problema, formulação do problema, implementação da ação, execução da ação, avaliação da ação e a continuidade da ação. A abordagem é de natureza qualitativa ao considerar as recomendações de Dezin e Lincoln (1994) que orientam o uso desse tipo abordagem quando se pretende compreender os fenômenos e seus significados no processo de implementação de metodologias em seus contextos naturais. Assim, o estudo de campo possui características descritivas (CRESSWELL, 2010; ACEVEDO E NOHARA, 2013), por de forma contextual, descrever as principais características de uma proposta didática-metodológica inovadora, ao envolver os alunos na construção de sua formação para empreender. 
Ao considerar os envolvidos, tem-se 12 professores tutores, 18 alunos tutores e 170 alunos envolvidos diretamente no projeto, perfazendo uma amostra de 200 alunos, oriundo de uma população de 260 , tendo em vista que os alunos participantes direto são os alunos de segundo ao oitavo período.

Os dados foram coletados por meio de observação direta, onde era analisado a integração dos conteúdos e sua aplicação na prática, e as narrativas das experiências desde a entrega do problema a execução final do projeto; resultado de avaliações - análise das informações coletadas nas avaliações realizadas a respeito dos conteúdos trabalhados em sala sobre a feira; relatórios - material produzido pelas equipes sobre as atividades desenvolvidas e entregue no final de cada evento pelos professores-tutores, alunos-tutores e os demais alunos participantes no período longitudinal de 2009 a 2017.

A integração de várias fontes, especialmente para implantação desse formato de trabalhar com metodologias ativas, possibilita o pesquisador uma diversidade de informações técnicas, comportamentais e atitudinais que analisadas de forma convergentes, possibilitam uma performance qualitativa dos resultados. Essa triangulação metodológica (Cresswell, Plano Clark, 2013; Flick, 2013) permite que o pesquisador tenha compreensões distintas do fenômeno estudo.

Ao que concerne a análise dos resultados, utilizou-se enquanto método, os direcionamentos de Bardin (2009) sobre análise de conteúdo como uma técnica de análise das comunicações que utiliza procedimentos sistemáticos e objetivos de descrição do conteúdo das mensagens. Nessa ótica, analisou-se as mensagens descritas pelos professores-tutores, alunos-tutores e os demais alunos envolvidos no processo.

\section{ANÁLISE DOS DADOS}

O projeto da EXPOVENDAS tem como objetivo desenvolver e orientar o comportamento empreendedor dos alunos por meio de discussões teóricas, lúdica e exposição prática de formação empreendedora nos mais distintos aspectos do empreendedorismo. Como uma atividade anual tem seus princípios de operacionalização discutidas no encontro pedagógico realizado uma semana antes de iniciar o semestre letivo.

O projeto é executado por meio da abordagem de metodologias ativas, especificamente uma adaptação para a aprendizagem baseada em problemas, considerado que cada ano é trabalhado uma temática onde a premissa é desenvolver a formação empreendedora do aluno por meio da seguinte indagação: Como fomentar a formação empreendedora num ambiente permeado por valores culturais do emprego tradicional?

Para isso, os professores-tutores iniciam um processo de discussões para em conjunto com os alunos-tutores identificarem o tema a ser trabalhado na perspectiva da formação para empreender. Após essa identificação, que envolvem 12 disciplinas, os professores tutores ingressam com uma associação interdisciplinar de conteúdos entre a base teórica da sua disciplina e a proposta prática do projeto.

Isso leva os alunos a apresentarem soluções práticas e aplicáveis para operacionalização da proposta. Então inicia um processo de envolvimento dos alunos na formação dos grupos e na habilidade da resolução do problema que resulta na concepção prática de apresentação de 18 stands com vendas e exposição de produtos para um público

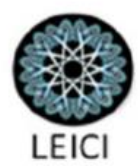


que inicialmente era dos alunos da instituição e que atualmente recebe um público que varia de 200 a 350 pessoas entre envolvidos no projeto e participação da sociedade.

As contribuições dessa metodologia ativa como processo de interação e construção do conhecimento, de tomada de decisão individual e coletiva obtida por meio da triangulação de dados, mostra relatos sobre os principais desafios encontrados em termos de potencialidades e dificuldades de introduzir a prática de formação empreendedora no cotidiano, na cultura e nos valores dos alunos, conforme relato de um aluno-tutor "participar do projeto é muito cansativo, mas quando as coisas começam a acontecerem a gente fica muito grato e passa a acreditar que não somos obrigados a formar nossa carreira somente no serviço público como a maioria dos nossos pais.".

Em relação aos anseios e aos desafios enfrentados durante o planejamento e a organização do projeto, foi possível extrair das observações diretas e por meio da integralização das informações entregues nos relatórios que "os alunos identificam dificuldades em relacionar os conhecimentos teóricos a vivência e aos problemas que surgem no decorrer da operacionalização". Segundo a afirmação de um grupo, "na hora de tomar a decisão, a equipe tem medo de estar agindo errado e comprometer o trabalho dos professores e expor a instituição". Esse posicionamento reforça as ideias de Dolabela; Filion, 2013; Lima et. al. 2015) ao afirmarem a urgente necessidade de uma reestruturação metodológica do ensino tradicional para um ensino em que o aluno possa contribuir de forma direta para a sua formação.

Sobre as emoções vivenciadas no dia do evento em detrimento as expectativas da coordenação, dos professores, do público e dos demais colegas participantes foi possível identificar " um alto grau de comprometimento, domínio das atividades, visão sistêmica, trabalho em equipe, motivação e interesse no resultado final" elementos essenciais para empreender (DORNELAS, 2001; DEGEN, 1989; HIRISCH; PETER, 2009).

$\mathrm{O}$ entendimento sobre as redes de relações para a qualidade do trabalho, essa percepção é identificada no relato de uma equipe "nós mapeamos os nossos conhecidos $e$ fomos pedir apoio para concretização de algumas ideias sobre decoração do stand, consignação dos produtos, palestrante, entre outros", é possível relacionar tais ações com os direcionamentos teóricos de McCLELLAND (1971).

Outro aspecto relevante com alto índice de indissociabilidade nos métodos foi o posicionamento de alguns grupos em relação a integração dos conhecimentos das outras disciplinas na resolução do problema. Com narrativa compatível entre os grupos "é que o conjunto de conhecimentos adquiridos nas disciplinas facilitou na tomada de decisão em relação a exposição dos produtos, qualidade dos serviços, postura dos alunos, definição do aluno-tutor[...] nos consideramos alguém com características de liderança, fluência verbal competente, conhecimentos que adquirimos nas disciplinas de gestão de pessoas, comunicação empresarial". Essa referência da interdisciplinaridade nos conduz as ideias de (Gadotti, 2004; Morin, 2005) ao defenderem a articulação das disciplinas como elemento orientador, atitudinal e gerador de pensamentos e ideias que fortalecem a formação profissional do aluno.

A coerência dos relatos advindos da prática aliada a teoria; e as sugestões de temas, formato e metodologia para o evento seguinte, também foram ressaltados, para maioria dos grupos "essa prática de responsabilizar os alunos para construir um projeto e apresentar

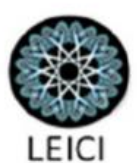


para a sociedade, é uma forma dos alunos descobrirem quais são as disciplinas que deixaram mais conhecimento e também nos mostra um cenário real, já que se a gente errar a responsabilidade é nossa, também é como se já fossemos profissionais, temos que planejar, organizar tudo e ainda deixar pronto para receber o público[...]pior é que na maioria das vezes a gente tem que tomar decisão na frente de todo mundo, da família e principalmente da professora[...]em um dos eventos o cliente quebrou um vazo que estava na decoração, tivemos vontade de pedir para ele pagar, mas decidimos assumir a responsabilidade”. Esse discurso corrobora com as ideias de Berbel (2011), ao defender que a aprendizagem ativa quando implementada com as ferramentas da Aprendizagem Baseada em Problemas oportuniza ao aluno um conjunto de conhecimentos advindo de situação de identificação e resolução de problemas, que orienta o aluno a um aprendizado significativo que contribui para a segurança da sua prática como futuro profissional.

Em relação a construção do conhecimento de forma ativa, mesmo mediante algumas instruções dos professores-tutores, inicialmente, alguns alunos, inclusive alunos-tutores apresentaram uma alta resistência quanto a ausência do professor, a consistência dessa carência está muito perceptível nesse relato de um grupo "precisamos do professor, se a gente já tivesse todo conhecimento não estaríamos fazendo o curso, é muito difícil tomar decisão sem perguntar ao professor". Ainda no âmbito dessa discussão, outra postura apresenta pelos alunos foi em relação as limitações de se expressar para a sociedade " a gente chega na empresa não sabe nem como começar a falar, então quando somos questionados sobre o propósito do que estamos querendo para nosso trabalho da faculdade, ficamos sem saber o que falar". A partir desses relatos, anualmente o projeto vai sendo adaptado. Uma das decisões em relação as dificuldades de expressão dos alunos quando estão contatando com empreendedores, empresários ou instituições de apoio, foi a formulação de um documento assinado pela coordenação do curso explicitando o propósito do trabalho, porém essa comunicação, deveria ser apresentada em situações emergenciais.

Entretanto, com o decorrer da aplicação do projeto, a forma de integração dos alunos com a proposta foi se tornando mais autônoma, colaborativa e com uso significativo das relações sociais, das suas habilidades pessoais. A referência a essa atuação está na narrativa de um grupo em relação as atividades avaliativas "esse trabalho é muito mais interessante pra nossa vida, do que aquele calendário de provas que somos obrigados a cumprir. Entendemos que a instituição pensa na nossa carreira, mas aprendemos mais quando a gente pensa o que pode dar certo para resolver a situação e metemos a cara". Esse posicionamento do grupo, nos direciona a ideia de Borhan (2014) ao relatar a importância do estimulo ao aluno para desenvolver seu senso crítico e habilidades de resolução de problemas por meio de uma prática ativa em que ele se sente o centro do processo e não agente receptor de informações. Isso nos remete ao pensamento de Freire (2003, p.34) ao citar o professor nesse processo de construção independente da aprendizagem do aluno "o docente não é responsável apenas para ensinar conteúdo, mas também ensinar a pensar certo". E formar um cidadão crítico, participativo e agente ativo da sua formação e contribuir para um pensamento adaptado a mudanças.

Outras expressões são identificadas durante a construção do projeto, entretanto, esse posicionamento foi identificado em dois momentos, no relatório e na observação direta em que uma equipe afirma que "ouvir o professor lendo slides e enfadonho e cansativo e logo a

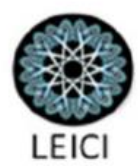


gente esquece, enquanto que esse trabalho é cansativo, nós que temos que fazer tudo, mas são momentos inesquecíveis, como aconteceu em 2014, quando fomos pedir suporte a APAE, vimos tantas crianças com dificuldades e nós reclamando por tão pouco". A partir dessas colocações cabe destacar o pensamento de Silva (2012) é preciso inserir no processo de construção do conhecimento do aluno, ações metodológicas pautadas em práxis educativas baseada na ordem social e cultural para oportunizar o aluno liberdade de expressão, compreensão e ação.

Em outro relato, um grupo expressou que " romper o medo de falar, aprender a receber não, ouvir mais, decidir sem a presença do professor, respeitar a ideia do colega, se responsabilizar por suas decisões, vale muito mais que passar horas lendo slide para fazer uma prova". Isso é romper com a educação bancária (Freire, 2005) e estimular o aluno aprender a aprender, explorar novos horizontes pessoais e profissionais, trabalhar de forma cooperativa, desenvolver habilidades para comunicação e participação em grupo (PERRENOUD, 2002; GRAFF; KOLMOS, 2007; BOTHA, 2010; BARBOSA, et al. 2013; CASALE, 2013).

Para os professores-tutores, "essa prática de envolver o aluno no processo da sua aprendizagem desenvolve o senso de responsabilidade de forma individual e coletiva". Essa oportunidade "cria uma relação mais segura entre professor e aluno". Na visão de alunotutor

"esse estimulo coloca o aluno com ator principal da sua prática, minha equipe fica preocupada em fazer as coisas de forma coerente as orientações e nossos conhecimentos, pensando no que as pessoas que vão nos visitar possa imaginar da gente, isso pode ficar difícil ou fácil para no futuro a gente conseguir um emprego melhor". Essa percepção coaduna com as ideias de Barbosa et al. (2013) sobre a interação do aluno com o assunto estudado, já que esse estimulo leva a construção do seu próprio conhecimento ao sair da função ator coadjuvante para ator principal, ou seja, da formação passiva para a ativa.

De acordo com um professor-tutor "essa interação prática em que é dado o aluno a responsabilidade por sua liberdade, iniciativa e executor, culmina em uma relação de troca numa perspectiva de ensino-aprendizagem baseado numa abordagem indutiva que promovendo uma aprendizagem mais sólida". Vigotsky (1998) considera que nesse tipo de aprendizagem, o aluno é o ser central e construtor do seu processo de aprendizagem, enquanto o professor atua como prospector estratégico que constrói junto com o aluno um ambiente propício à sua aprendizagem e o professor atua como o mediado dessa construção independente.

\section{CONSIDERAÇÕES FINAIS}

Existe uma constatação recorrente no desenvolvimento da formação empreendedora por meio da educação básica e superior (ROCHA; BACHI, 2010; ROCHA ET AL, 2011;LIMA et al.,. 2014; AZEVEDO; MANTHEY; LENZI, 2016). Nesse sentido, a 
Expovendas contribui para a formação da formação empreendedora ao romper com algumas práticas do ensino tradicional e transpor barreiras culturais, metodológicas e sociais deixando para trás muito da educação bancária (Freire, 2005) levando professores e alunos a uma reflexão sobre o fazer educação por meio de uma prática progressista (Libâneo, 2008) que induz o aluno a vivenciar uma formação empreendedora que facilita o desenvolvimento pessoal e profissional.

O projeto Expovendas por mais que provoque ansiedade aos professores-tutores e alunos, revelou-se como uma prática que vem fortalecendo a criticidade dos alunos engajados nesse modelo de formação empreendedora voltada para o agir sobre o mundo com o objetivo de proporcionar uma mudança no cenário vigente e ao mesmo tempo assumir o papel de agente formador da sua prática.

A aplicação da metodologia Aprendizagem Baseada em Problemas propiciou aos alunos relacionar os conteúdos a uma formação empreendedora prática e dinâmica ao experimentarem situações problemas pertinentes ao cotidiano de um profissional que vive no mercado em constante mutabilidade.

No contexto geral, o uso dessa metodologia ativa tornou-se para os alunos uma janela de oportunidades ao desenvolver a capacidade crítica e autonomia para expressar suas habilidades e competências enquanto agente construtor da sua própria aprendizagem otimizando a sua capacidade para empreender. Para os professores oportunizou a construção de um conhecimento compartilhado em que o mesmo saiu da condição de transmissor para formador de um ambiente que propicie elementos que estimule e envolva o aluno a viver experiências que leve a aprendizagem efetiva.

Observa-se comprometimento e envolvimento nas atividades de caráter empreendedora; Criação de compartilhamento de ideias e informações entre alunos e professores; Alinhamento entre as experiências profissionais e a prática em sala de aula, bem como as reflexões dos professores ao implementarem uma prática geradora de conhecimento e de possíveis oportunidades para futuras mudanças sociais e econômicas da região.

É salutar informar que ao longo da efetivação anual desse projeto, algumas limitações tornaram-se assídua, outras foram se formando ao longo da construção. Ainda é recorrente a resistência do envolvimento de alguns alunos no desempenho das suas atividades individuais, gerando uma descontinuidade no processo de aprendizagem do grupo. A dinâmica de adaptação da metodologia ativa ao ensino tradicional ainda compromete a proposta final do projeto.

Observa-se que, pelo fato dos alunos anualmente participarem do projeto, a aprendizagem torna-se repetitiva para alguns, entretanto, outros demonstram um avanço significativo que pode ser mensurado por meio das manifestações de gratidão atribuídas aos professores nos discursos de colação de grau e, especificamente nos 22 profissionaisempreendedores por oportunidades egressos do curso e 13 por necessidade (Setor de egressos, 2016), e 17 empreendedores em fase de formação com a intenção de empreender, conforme pesquisa realizada no ato da matrícula pela instituição de ensino em 2017.

Com base na aplicação e nos resultados obtidos no decorrer da implementação do projeto EXPOVENDAS por meio do uso da metodologia ativa aprendizagem Baseada em Problemas, sugere-se que esse formato seja aplicado em grupos menores e com distintas problemáticas na área de formação para empreender na perspectiva do terceiro setor,

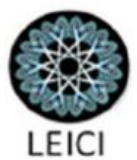


empreendedorismo jovem, e a interface entre universidade e empresa dentre outras oportunidades de pesquisas que surgem de acordo com as potencialidades da região em que a instituição está inserida.

\section{REFERÊNCIAS}

ARAÚJO, U. F. Temas Transversais e a estratégia de projetos. Editora Moderna, 8o edição, 2008.

AZEVEDO, A.C.;MANTHEY, N.B.; LENZ, F.F.O ensino do empreendedorismo em cursos de graduação: panorama das práticas dos cursos de ciências sociais aplicadas. IX Encontro de Estudos sobre Empreendedorismo e Gestão de Pequenas Empresas - EGEPE. Passo Fundo - Rio Grande do Sul, 2016. Disponível em: http://www.egepe.org.br/2016/artigosegepe/331.pdf. Acesso em 22/02/2017.

BARDIN, L. Análise de Conteúdo. Lisboa, Portugal; Edições 70, LDA, 2009.

BARON, Robert A.; SHANE. Scott A. Empreendedorismo: uma visão do processo. São Paulo: Thompson Learning, 2007.

BERBEL, N.A. N. As metodologias ativas e a promoção da autonomia de estudantes. Seminário Ciências Sociais e Humanas (Online), v. 32, p. 01-25, 2011. Disponível em: http://www.uel.br/revistas/uel/index.php/seminasoc/article/view/10326 acessado em 05 de fevereiro de 2018.

BOTHA, M. A project-based learning approach as a method of teaching entrepreneurship to a large group of undergraduate students in South Africa. Education as Change, 14 (2). pp. 213 232, 2010.

CASALE, A. Aprendizagem Baseada em Problemas - desenvolvimento de competências para o ensino em engenharia. 173 f. Tese (Doutorado) - Escola de Engenharia de São Carlos, Universidade de São Paulo, São Carlos, 2013.

CHIZZOTTI, A. Pesquisa qualitativa em ciências humanas e sociais. Petrópolis: Vozes, 2006

DELORS, Jacques et al. Educação: um tesouro a descobrir. 10. ed. São Paulo: Cortez; Brasília, DF: UNESCO, 2006.

DEMO, Pedro. Habilidades e competências no século XXI. Porto Alegre: Mediação, 2010.

FLICK, U. Introdução à metodologia de pesquisa. Porto Alegre: Penso, 2013.

FREIRE, P. Pedagogia do Oprimido, $43^{\text {a }}$ ed. Rio de Janeiro, Paz e Terra, 2005.

FREIRE, Paulo. Pedagogia da autonomia: saberes necessários à prática docente. São Paulo: Paz e Terra, 2003

GADOTTI, M. Interdisciplinaridade: atitude e método. São Paulo:2004. Instituto Paulo Freire.Disponível em : https://www.paulofreire.org. Acessado em 14 de março de 2018.

GLOBAL ENTREPRENEURSHIP MONITOR. Empreendedorismo no Brasil - Relatório executivo. 2015

GRAAFF, E. d.; KOLMOS, A. (Eds.). Management of Change: Implementation of ProblemBased and Project-Based Learning in Engineering. Roterdam: Sense Publishers, 20017. HASHIMOTO, M. Centros de empreendedorismo no Brasil. São Paulo: SebraeSP, 2013. HERNÁNDEZ, Fernando; VENTURA, Montserrat. A organização do currículo por projetos de trabalho: o conhecimento é um caleidoscópio. Porto Alegre: Artes Médicas, 1998. 
KNOLL, M.The project method: Its vocational education origin and international development. Journal of Industrial Teacher Education, 34(3), 59-80, 1997.

KOLB, D. A.Experiential learning: experience as the source of learning and development. New Jersey: Prentice Hall Inc. 1984.

LIBÂNEO, J. C. Adeus professor, Adeus professora? Novas exigências educacionais e profissão docente. Coleção Questões da nossa Época, v.2, Ed. São Paulo: Cortez, 2011

LIBÂNEO, José Carlos. Organização e gestão da escola: teoria e prática. 5. ed. Goiânia: MF Livros, 2008.

LIMA, E. et al. Educação superior em empreendedorismo e intenções empreendedoras dos estudantes - Relatório do Estudo GUESSS Brasil 2013-2014. Grupo APOE - Grupo de Estudo sobre Administração de Pequenas Organizações e Empreendedorismo, PPGAUNINOVE. Caderno de pesquisa, n. 2014-03. São Paulo: Grupo APOE. 2014.

LIMA, Edmilson; LOPES, R. M. A.; NASSIF, V. M. J.; SILVA, Dirceu. Opportunities to Improve Entrepreneurship Education: Contributions Considering Brazilian Challenges. Journal of Small Business Management, v. 53, p. 1033-1051, 2015.

MORÁN, J. M. Mudando a educação com metodologias ativas. Coleção Mídias Contemporâneas. Convergências Midiáticas, Educação e Cidadania: aproximações jovens. Vol. II. Carlos Alberto de Souza e Ofelia Elisa Torres Morales (orgs.), 2015

MORIN, Edgar. Educação e complexidade, os sete saberes e outros ensaios. São Paulo: Cortez, 2005..

SHANE, S.; VENKATARAMAN, S. The promise of entrepreneurship as a field of research. Academy of Management Review, v. 25, n. 1, p. 217-226, jan. 2000.

TSCHÁ, E. R.; CRUZ NETO, G.G. Empreendendo colaborativamente ideias, sonhos, vidas, e carreiras: o caso das células empreendedoras. In: BECKER, A. R. Educação Empreendedora: a formação de futuros líderes. In: GIMENEZ, F. A. P. et. al. (org.) Educação para o empreendedorismo. Curitiba: Agência de Inovação da UFPR, 2014.

VANEVENHOVEN, Jeff. Advances and Challenges in Entrepreneurship Education. Journal of Small Business Management, 2013. 